\title{
PELAKSANAAN SUPERVISI OLEH KEPALA SEKOLAH
} DAN PENGAWAS SEKOLAH

\author{
${ }^{1}$ Nurfatah, $\boldsymbol{\&}^{2}$ Nur Rahmad \\ ${ }^{1}$ SD Negeri 8 Talang Kelapa ${ }^{2}$ Peneliti Independen Kota Palembang \\ e-mail: ${ }^{1}$ nurfatah72@gmail.com ${ }^{2}$ nurrahmat477@gmail.com
}

\begin{abstract}
Technical assistance is provided to teachers as an ongoing capacity building effort. The assistance is in the form of academic supervision by principals and school supervisors. The school supervisor also does managerial supervision to the principal. This research is a qualitative research with case study. The research was conducted at SDN 8 Talang kelapa. The result of the research was the supervision of principal and school supervisor has made better performance of teacher. It was seen from the good preparation of learning equipment. While the implementation of learning has not been completely good because it still uses the old methods such as lecturing and assignments. There were still $15 \%$ of teachers who nervous when it will be supervised, this caused by several factors 1) teachers who are almost retired, an average age of 55 years and above; 2) teachers who lack the computer. The difference between principal supervision and supervision of school supervisors lies in subjects supervised, implementation schedule, and follow-up.
\end{abstract}

Keywords: Supervision; Principal; Schools Supervisor

\section{PENDAHULUAN}

Undang-Undang Nomor 20 Tahun

2003 tentang Sistem Pendidikan Nasional menyatakan bahwa Pendidikan adalah usaha sadar dan terencana untuk mewujudkan suasana belajar dan proses pembelajaran, agar peserta didik secara aktif mengembangkan potensi dirinya untuk memiliki kekuatan spiritual keagamaan, pengendalian diri, kepribadian, kecerdasan, akhlak mulia, serta keterampilan yang diperlukan dirinya, masyarakat, bangsa dan negara. Pendidikan nasional bertujuan untuk berkembangnya potensi peserta didik agar menjadi manusia yang beriman dan bertaqwa kepada Tuhan Yang Mahaesa, berakhlak mulia, sehat, berilmu, cakap, kreatif, mandiri, dan menjadi warga negara yang demokratis serta bertanggung jawab.
Kegiatan utama pendidikan di sekolah dalam rangka mewujudkan tujuannya adalah kegiatan pembelajaran, sehingga seluruh aktifitas organisasi sekolah bermuara pada pencapaian efisiensi dan efektifitas pembelajaran. Upaya peningkatkan kualitas sumber daya manusia salah satunya melalui proses pembelajaran di sekolah. Guru merupakan komponen sumber daya manusia dalam bidang pendidikan yang harus dibina dan dikembangkan terus menerus. Agar para guru mampu melaksanakan tugas-tugas yang menjadi tanggung jawabnya di sekolah perlu senantiasa mendapat penyegaran dalam bentuk bantuan teknis. Bantuan teknis ini diberikan kepada guru sebagai upaya peningkatan kapasitas secara terus menerus. Bantuan tersebut dalam bentuk supervisi 
akademik yang dilakukan oleh kepala sekolah dan pengawas sekolah hal ini sesuai dengan hasil penelitian Ramadhan (2017) pelaksanaan supervisi akademik pengawas sekolah dan supervisi kepala sekolah secara bersama-sama berpengaruh signifikan terhadap kinerja guru SMK Negeri di Kabupaten Majene.

Salah satu tugas kepala sekolah adalah sebagai supervisor yaitu mensupervisi pekerjaan yang dilakukan oleh tenaga kependidikan. Menurut pendapat Sergiovani dan Starrat dalam Mulyasa (2006:11) menyatakan bahwa "supervision is process designed to help teacher and supervisor leam more about their practice; to better able to use their knowledge and skills to better serve parents and schools; and to make the school a more effective learning community".

Supervisi perlu diberikan kepada guru karena merupakan makhluh sosial sejak lahir membutuhkan bantuan orang lain untuk tetap hidup, tumbuh dan berkembang. Dengan katalain manusia membutuhkan orang lain untuk dapat hidup dan berkembang dan dipengaruhi oleh normanorma kelompok atau masyarakatnya. Bila norma-norma kelompok ini baik, maka orang dalam kelompok cenderung manjadi baik (Risnawati, 2014: 2011).

Pengawas sekolah mempunyai peran yang sangat besar dalam mendukung peningkatan kualitas pendidikan di sekolah dan di daerah yang menjadi binaannya. Peran pengawas sekolah dalam mengembangkan kualitas pendidikan di sebuah sekolah melalui pembinaan di bidang akademik dan manajerial merupakan kebutuhan utama suatu sekolah untuk meraih prestasi dalam rangka menghasilkan sumberdaya manusia unggul dan berdaya saing. Selain itu, peran strategis pengawas sekolah adalah membina kemampuan profesional kepala sekolah dan guru. Hal ini sesuai dengan penelitian Sudin (2008) pengawas dalam menjalankan tugasnya sebagai pembina dalam meningkatkan guru mata pelajaran masuk katagori cukup, baik pelaksanaan manajemen kelas, akademik, maupun pengembangan profesi guru.

Visi sekolah SDN 8 Talang Kelapa mejadi sekolah yang Berkarakter, Berprestasi, Disiplin dan Inklusif, sedang misinya adalah 1) menyiapkan generasi unggul yang memiliki potensi dibidang IMTAQ dan IPTEK; 2) membentuk sumber daya manusia yang aktif, kreatif, inovatif sesuai dengan perkembangan zaman; 3). membangun citra sekolah sebagai mitra terpercaya masyarakat; 4) mengembangkan sekolah Inklusi ramah anak. Sebagai upaya untuk mencapai visi dan misi sekolah SDN 8 Talang Kelapa yang telah di tetapkan tentunya memerlukan sumberdaya manusia (Kepala sekolah,guru, tenaga kependidikan) 
yang profesional dan memiliki kinerja yang baik, hal ini di dukung oleh adanya supervisi yang dari kepala sekolah dan pengawas sekolah. Hal inilah yang menjadikan pentingnya penelitian ini pelaksanaan supervisi kepala sekolah dan pengawas sekolah di SDN 8 Talang Kelapa apakah sudah berjalan sebagaimana mestinya ataukah sebaliknya.

\section{SUPERVISI}

Secara etimologis supervisi terdiri atas dua kata, super (lebih) dan vision (pandangan). Dengan kata lain supervisi mengandung arti pandangan yang lebih. Pengertian ini mengisyaratkan bahwa supervisi dilakukan oleh pihak yang memiliki kedudukan yang lebih tinggi dari pihak yang disupervisi.

Supervisi pendidikan sebenarnya adalah bantuan dalam mengembangkan situasi pembelajaran kearah yang lebih baik, dengan jalan memberikan bimbingan dan pengarahan pada guru-guru dan petugas lainnya untuk meningkatkan kualitas kerja mereka dibidang pengajaran dan segala aspeknya (Risnawati, 2014: 214). Pendapat lain menurut Kimball Wiles dalam (Maryono, 2011) menyatakan bahwa "Supervision is assistance in the development of a better teaching learning situation”. Supervisi adalah proses bantuan untuk meningkatkan situasi belajar mengajar agar lebih baik. Pengertian ini menunjukkan bahwa supervisi adalah proses bantuan, bimbingan,dan atau pembinaan supervisor kepada guru untuk memperbaiki proses pembelajaran.

Melalui supervisi, diharapkan seorang guru dapat; 1) bekerja keras dan demokratis; 2) ramah dan suka mendengarkan orang lain; 3) sabar; 4) luas pandangan dan menaruh perhatian kepada orang lain; 5) penampilan pribadi yang menyenangkan dan sopan santun; 6) jujur; 7) suka humor; 8) kemampuan kerja yang baik dan konsisten; 9) menaruh perhatian pada problem siswa; 10) fleksibel dalam cara mengajar; 11) bisa menggunakan pujian dan mau memperbaiki; 12) pandai dalam mengajar pada bidang studi (Sahertian, 1994). Supervisi agar bisa berjalan dengan baik harus memperhatikan prinsip-prinsip supervisi, dalam hal ini Mulyasa (2006:113) menyebutkan prinsipprinsip supervisi adalah; 1) hubungan konsultatis, kolegial dan bukan herarkis; 2) dilaksanakan secara demokratis; 3) berpusat pada tenaga kependidikan/guru); 4) di lakukan berdasarkan kebutuhan tenaga kependidikan (guru); 5) merupakan bantuan professional.

Pelaksanaan supervisi tidak hanya mendatangi guru dan memeriksa berkas atau melihat pelaksanaan mengajar dikelas, hal ini sesuai pandapat Marshall (2009) perlu secara drastis memikir ulang model 
supervisi yang ada selama ini untuk mencapai hasil pembelajaran yang baik. Tujuh poin berikut merupakan jarak antara ideal dan kenyataan: 1). kepala sekolah dan guru telah berbagi pemahaman apa hal yang baik dalam mengajar; 2). kepala sekolah masuk ke kelas dan melihat tipe mengajar guru dalam praktiknya; 3). kepala sekolah perlu memetakan dan mengingat poin kunci dalam kunjungan kelasnya; 4). kepala sekolah memberi umpan balik kepada guru mengenai apa yang efektif dan apa yang dibutuhkan untuk ditingkatkan; 5). guru memahami dan menerima umpan balik; 6). Guru menggunakan umpan balik untuk memperbaiki praktik mengajar guru; 7). Sebagai hasilnya prestasi siswa meningkat.

Supervisi klinis berbeda dengan supervisi akademik bedanya supervisi klinis sebagai upaya yang dirancang secara rasional dan praktis untuk memperbaiki performansi guru di kelas dengan tujuan untuk mengembangkan profesional guru dan perbaikan pengajaran. Jadi, supervisi klinis dirancang untuk memperbaiki dan memgembangkan pengajaran melalui pengembangan professional guru Cogan dalam (Sagala,2012).

Dalam pelaksanaannya supervisi klinis terbagi menjadi tiga tahapan, yakni kegiatan awal, observasi mengajar, dan pertemuan balikan. Pertama, pertemuan awal (precomference), yaitu membahas kontrak kerja untuk melakukan observasi kelas pada saat guru mengajar. Kedua, tahapan observasi kelas, yakni melakukan pengamatan pada saat guru melaksanakan pembelajaran. Ketiga, tahap pertemuan balikan (post coference), yaitu tahap analisis observasi yang dilakukan supervisor guna memberikan solusi pada masalah yang terjadi dalam pembelajaran (Imron, 2011). Perbedaannya adalah supervisi akademik dilakukan dengan inisiatif supervisor, sedangkan supervisi klinis inisiatif awal datangnya dari kesadaran guru. Pada konsepnya supervisi klinis dianalogikan dengan seorang pasien yang sakit dan menginginkan kesembuhan dari penyakitnya, lalu ia datang ke dokter untuk diobati (Prasojo dan Sudiyono, 2011).

\section{KEPALA SEKOLAH}

Permendiknas Nomor 13 tahun 2007 tentang Standar Kepala Sekolah/Madrasah meliputi kompetensi kepribadian, sosial, manajerial, kewirausahaan, dan supervisi. Sebagai manager kepala sekolah mengelola sekolah guna mencapai tujuan pendidikan hal ini sesuai dengan pendapat Hersey dan blanchard dalam (Risnawati, 2012) mengartikan istilah manajemen itu dengan kegiatan yang dilakukan bersama orang lain atau melelui orang lain atau kelompok dengan maksud untuk mencapai tujuantujuan organisasi. 
Dalam Keputusan Menteri Pendidikan Nasional RI Nomor 162/U/2003 tentang Pedoman Penugasan Guru sebagai Kepala Sekolah yang disebut "Emaslim" (edukator, manajer, administrator, supervisor, leader, inovator, dan motivator). Salah satu standar dan tugas kepala sekolah adalah kompetensi supervisi. Kompetensi tersebut yaitu: (1) merencanakan program supervisi akademik dalam rangka peningkatan pro-fesionalisme guru; (2) melaksanakan supervisi akademik terhadap guru dengan menggunakan pendekatan dan teknik supervisi yang tepat; (3) menindaklanjuti hasil supervisi akademik terhadap guru dalam rangka peningkatan profesionalisme guru. Kepala sekolah berperan dalam pengelolaan sekolah hal ini sesuai dengan pendapat Supardi (2012: 13) bahwa, "kepemimpinan kepala sekolah melalui pemberian layanan supervisi kepada guru merupakan salah satu variabel organisasi yang mempengaruhi kinerja guru". Kepala sekolah agar efektif dalam pelaksanaan supervisi perlu dimanajemen dengan baik hal ini sesuai dengan penelitian Sari dan Sukoco (2015) melalui perencanaan yang baik secara umum supervisi akademik oleh kepala sekolah dasar negeri sekecamatan Talang Empat, Bengkulu Tengah efektif.

Menurut Robbins \& Alvy dalam (:2004) bahwa supervisi untuk meningkatkan belajar siswa melalui pembangunan pengawasan dan profesional. Supervisi akademik dilakukan untuk mengetahui guru dalam melaksanakan kegiatan pembelajaran mulai dari kegiatan perencanaan, pelaksanaan, dan penilaian. Kepala sekolah dapat mengetahui kompetensi dan kinerja guru dalam kegiatan pembelajaran dari masing-masing guru melalui kegiatan monitoring, pemantauan dan pengawasan pembelajaran di kelas. Hasil pemantauan atau yang selanjutnya disebut dengan hasil supervisi tersebut, digunakan untuk menyusun program tindak lanjut supervisi berikutnya. Program tindak lanjut tersebut diberikan kepada semua guru baik yang sudah ber-kinerja tinggi maupun yang masih memerlukan pembinaan dan pengawasan secara intensif.

Kompetensi supervisi kepala sekolah berdasarkan Permendiknas no 13 tahun 2007 diantaranya; 1) merencanakan program supervisi akademik dalam rangka peningkatan profesionalisme guru; 2) melaksanakan supervisi akademik terhadap guru dengan menggunakan pendekatan dan teknik supervisi yang tepat; 3) menindaklanjuti hasil supervisi akademik terhadap guru dalam rangka peningkatan profesionalisme guru. Hal ini sesuai dengan Mulyasa (2006: 112) kepala sekolah sebagai supervisor dalam kemampuan menyusun, melaksanakan program supervisi serta memanfaatkan hasilnya. 


\section{PENGAWAS SEKOLAH}

Dalam memajukan pendidikan ada unsur guru kepala sekolah dan pengawas sekolah. Pengawas sekolah adalah tenaga kependidikan profesional yang diberi tugas, tanggung jawab dan wewenang secara penuh oleh pejabat yang berwewenang untuk melakukan pembinaan dan pengawasan dalam bidang akademik (teknis pendidikan) maupun bidang manajerial /pengelolaan sekoah (Sagala:2012: 138). Disebutkan tugas pokok pangawas sekolah berdasarkan Peraturan Pemerintah RI Nomor. 19 Tahun 2005, Tentang Standar Nasional Pendidikan, pada Pasal 55 menyatakan bahwa, "pengawasan satuan pendidikan meliputi pemantauan, supervisi, evaluasi, pelaporan dan tindak lanjut hasil pengawasan”. Peran kepala sekolah begitu penting seperti pendapat Sagala (2012) pengawas sekolah memberikan pembinaan, penilaian, dan bantuan/bimbingan mulai dari rencana program, proses, sampai dengan hasil dalam pengelolaan sekolah untuk meningkatkan kinerja sekolah, sedangkan tanggungjawab sebagai pengawas adalah membantu meningkatkan kualitas penyelenggaraan pendidikan (supervisi manajerial), pengawas sekolah juga bertugas membantu meningkatkan kualitas proses belajar mengajar/membimbing dan hasil prestasi belajar siswa dalam rangka mencapai tujuan pendidikan.
Bedasarkan Badan Standar Nasional Pendidikan dalam Risnawati (2014 : 162163) ada tujuh kemampuan dasar yang harus dimiliki pengawas sekolah dalam membina kepala sekolah, yaitu: 1) Membantu penyusunan rencana pengembangan sekolah (termasuk menetapkan visi, misi, tujuan, sasaran, indicator keberhasilan, arah dan strategi, kebijakan internal, dan program kerjanya); 2) Memantau pengelolaan sistem kode etik dan tata laku semua subjek pendidikan meliputi pendidik, tenaga kependidikan, dan siswa/peserta didik; 3) Memfasilitasi pengambilan keputusan demokratik, partisipatif, dan kolektif; 4) Membimbing pengembangan kurikulum dan silabus secara dinamik dan berkelanjutan sesuai dengan kebutuhan pencapaian peningkatan mutu pendidikan; 5) Memantau pelaksanaan program pendidikan berorientasi kepada peningkatan mutu pendidikan yang memperhatikan baik unsur masukan, proses, dan hasil/output pendidikan; 6) Mengarahkan pendelegasian dan pendistribusian tugas, wewenang, dan tanggung jawab secara proporsional dan konsisten; 7) Mendorong pengelolaan seluruh sumber daya pendidikan termasuk dana.

Kompetensi supervisi pengawas menurut permendiknas no 12 tahun 2007 tentang Standar Pengawas Sekolah/Madrasah ada dua yaitu kompetensi 
supervisi manajerial dan kompetensi supervisi akademik . Kompetensi supervise manajerial terdiri dari;.1) menguasai metode, teknik dan prinsip-prinsip supervisi dalam rangka meningkatkan mutu pendidikan di sekolah; 2) menyusun program kepengawasan berdasarkan visimisi-tujuan dan program pendidikan di sekolah; 3) menyusun metode kerja dan instrument yang diperlukan untuk melaksanakan tugas pokok dan fungsi pengawasan di sekolah; 4 Menyusun laporan hasil-hasil

pengawasandan menindaklanjutinya untuk perbaikan program pengawasan berikutnya di sekolah; 5) membina kepala sekolah dalam pengelolaan dan administrasi satuan pendidikan berdasarkan manajemen peningkatan mutu pendidikan di sekola; 6) membina kepala sekolah dan guru dalam melaksanakan bimbingan konseling di sekolah; 7 mendorong guru dan kepala sekolah dalam merefleksikan hasil-hasil yang dicapainya untuk menemukan kelebihan dan kekurangan dalam melaksanakan tugas pokoknya di sekolah.

Sedang Kompetensi supervise akademik untuk pengawas (TK/SD/MI) adalah; 1) Memahami konsep, prinsip, teori dasar, karakteristik, dan kecenderungan perkembangan tiap bidang pengembangan di TK/RA atau mata pelajaran di SD/MI; 2 ) memahami konsep, prinsip, teori/teknologi, karakteristik, dan kecenderungan, perkembangan proses pembelajaran/ bimbingan tiap bidang pengembangan di TK/RA atau mata pelajaran di SD/MI; 3) membimbing guru dalam menyusun silabus tiap bidang pengembangan di TK/RA atau mata pelajaran di SD/MI berlandaskan standar isi, standar kompetensi dan kompetensi dasar, dan prinsip-prinsip pengembangan KTSP; 4) membimbing guru dalam memilih dan menggunakan strategi/ metode/ teknik pembelajaran/ bimbingan yang dapat mengembangkan berbagai potensi siswa melalui bidang pengembangan di TK/RA atau mata pelajaran di SD/MI; 5) membimbing guru dalam menyusun rencana pelaksanaan pembelajaran (RPP) untuk tiap bidang pengembangan di TK/RA atau mata pelajaran di SD/MI; 6) membimbing guru dalam melaksanakan kegiatan pembelajaran/ bimbingan (di kelas, laboratorium, dan/atau di lapangan) untuk mengembangkan potensi siswa pada tiap bidang pengembangan di TK/RA atau mata pelajaran di SD/MI; 7) membimbing guru dalam mengelola, merawat, mengembangkan dan menggunakan media pendidikan dan fasilitas pembelajaran/ bimbingan tiap bidang pengembangan di TK/RA atau mata pelajaran di SD/MI; 8) Memotivasi guru untuk memanfaatkan teknologi informasi untuk pembelajaran/ bimbingan tiap bidang 
pengembangan di TK/RA atau mata pelajaran SD/MI.

\section{METODE PENELITIAN}

Penelitian ini merupakan penelitian kualitatif dengan studi kasus (case study). Penelitian kualitatif menurut Kristiawan dan Elnanda (2017) merupakan one of research procedure that produces descriptive data in form of words, writing, and behavior of the people being observed. Sedangkan case study menurut Yuliani dan Kristiawan (2017) meruapakan suatu metode untuk memahami individu yang dilakukan secara integratif dan komprehensif agar diperoleh pemahaman yang mendalam tentang individu tersebut beserta masalah yang dihadapinya. Menurut Nazir (2009: 57) case study adalah peneltian tentang status subyek penelitian yang berkenaan dengan suatu fase suatu fase spesifik atau khas dari keseluruhan personalitas. Penelitian dilakukan di SDN 8 Talang kelapa yang terletak di jalan Palembang-Betung KM 14 Kecamatan Talang Kelapa Kabupaten Banyuasin. Sumber- sumber data penelitian ini adalah kepala sekolah, pengawas sekolah dan guru-guru di lingkungan SDN 8 Talang Kelapa.

Pengumpulan data dilakukan dengan teknik observasi, wawancara, dan dokumentasi. Data yang terkumpul kemudian dianalisis dengan menggunakan teknik analisis data interaktif yang terdiri dari tiga kegiatan yang saling berinteraksi, yaitu reduksi data, penyajian data, dan penarikan kesimpulan atau verifikasi (Sugiyono, 2007: 337).

Peneliti mendeskripsikan sesuatu yang terjadi pada sasaran penelitian yang merupakan kata-kata, tingkah laku atau aktivitas dan realitas dari sumber penelitian. Oleh karena itu penelitian kualitatif dilakukan pada kondisi alamiah bersifat penemuan sehingga peneliti merupakan instrument kunci. Peneliti bertanya, menganalisa, dan mengkonstruksikan objek yang diteliti berhubungan dengan pelaksanaan supervisi oleh kepala sekolah dan pengawas sekolah.

\section{HASIL PENELITIAN DAN PEMBAHASAN}

Dalam pelaksanaan supervisi di SDN 8 Talang Kelapa dilakukan oleh kepala sekolah dan pengawas sekolah. kepala sekolah Ibu Idayanti,S.Pd dan pengawas sekolah Bapak Drs.H. Rozali, M.Si. Dalam melaksanakan supervisi kepala sekolah menyusun program supervisi tahun 2017/2018, diantaranya berisi cover depan, identitas sekolah (berisi alamat Jalan Palembang-Betung KM 15, tahun berdiri 1976, jumlah rombongan belajar ada 18, jumlah siswa ada 661 siswa, tenaga pendidik ada 23 PNS, 3 orang guru honor, 2 orang Pembina ekstra kurikuler, Tenaga 
kependidikan terdiri dari satu penjaga sekolah dan 2 tenaga operator $\mathrm{TU}$ dan 1 pengelola perpustakaan. Kemudian profil sekolah diantaranya berisi akreditasi sekolah "B", pendahuluan tujuan supervisi akademik, manfaat,Jadwal supervisi akademik yaitu dimulai dari tanggal 4 September 2017 sampai dengan 26 September 2017. Dalam perencanaan ini dimulai dari guru kelas I sd kelas VI baru guru bidang studi agama dan penjaskes. Lampiran berisi administrasi perencanaan pembelajaran, penilaian RPP, lembar observasi/pengamatan pembelajaran, pengolahan hasil pengamatan.

Pelaksanaan supervisi kepala sekolah membagikan jadwal supervisi dan sesuai dengan jadwal mengadakan supervisi kepada guru. Adapun yang di supervisi administrasi perencanaan pembelajaran yang berisi komponen dengan baik walau jadwalnya ada yang berubah dikarenakan ada kegiatan lain sehingga di alihkan hari lain, tetapi guru juga mengerti (wawancara dengan kepala sekolah, tanggal 4 Desember 2017).

Hasil penelitian ini didukung oleh penelitian (Karsiyem dan M.Nur Wangit, 2015) bahwa supervisi akademik meliputi perencanaan pembelajaran, pelaksanaan pembelajaran, dan penilaian pembelajaran. Di awal semester ada kegiatan workshop K13 sebagai tindak lanjut dari hasil supervisi semester sebelumnya diketahui bahwa baru guru kelas I,IV,V yang sudah mengikuti pelatihan kurikulum K-13. Dengan melihat masih adanya guru yang belum memahami K13 maka kepala sekolah mengundang narasumber ibu Rosnani,M.Pd guna mengadakan workshop K-13 yang dilaksanakan tiga kali pertemuan tiap hari sabtu di bulan September di minggu I,II,III (wawancara dengan kepala sekolah 4 september 2014). Rata-rata guru sudah menyiapkan administrasi pembelajaran namun dalam pelaksanaan pembelajaran guru masih banyak yang menggunakan caracara lama yaitu murid membaca buku guru menjelaskan dan di akhiri mengerjakan soal. Hal ini di karenakan masih banyaknya guru yang belum menguasai computer, dan belum memanfaatkan TIK dalam pembelajaran.

Sarana prasarana guna menunjang pembelajaran yang lebih baik memang belum memadai LCD 2 buah, kemudian metode mengajar, media juga masih perlu di kembangkan lagi agar proses balajar menjadi pembelajaran yang aktif,kreatif dan menyenangkan (PAIKEM). Dari hasil wawancara dengan guru ada $15 \%$ guru yang nerveus ketika akan di supervisi hai ini disebabkan beberapa faktor; 1) guru yang hampir pensiun rata-rata usianya 55 tahun keatas; 2) guru yang kurang menguasai computer/ IT (wawancara dengan guru kelas 
I Ibu Sugiarti, S.Pd Tanggal 4 Desember 2017).

Supervisi guru telah menjadikan guru kinerjanya lebih baik, terlihat dari penyusunan perangkat pembelajaran sudah baik, pelaksanan pembelajaran belum sepenuhnya baik karena masih menggunakan metode-metode yang lama seperti ceramah, penugasan. Dari administrasi juga tertib dari daftar hadir, daftar nilai dan lain-lainnya. Secara umum dengan adanya supervisi akademik meningkatkan kinerja guru terlihat dari ratarata nilai supervisi baik hal ini sesuai dengan penelitian (Ramadhan, 2017) bahwa supervisi kepala sekolah berpengaruh signifikan terhadap kinerja guru. Selama ini belum ada guru yang minta supervisi klinis untuk memecahkan permasalahan yang dihadapi guru, hal ini disebabkan guru malu dianggap mampu (Wawancara dengan Kepala Sekolah Tanggal 6 Desember 2017).

Supervisi pengawas di SDN 8 Talang Kelapa dalam pelaksanaannya terdiri atas supervisi manajerial; yaitu supervisi kepada kepala sekolah yang berkaitan dengan kepala sekolah sebagai manajer di sekolah. Sebagai manajer kepala sekolah melakukan kegiatan merencanakan, menyusun, mengadministrasi, mengontrol, evaluasi segala kegiatan yag ada di sekolah baik administrasi siswa, administrasi, keuangan, administrasi tenaga pendidik, administrasi tenaga kependidikan, administrasi kurikulum. Supervisi akademik dilakukan pengawas sekolah kepada guru-guru di SDN 8 Talang Kelapa. Pengawas sekolah memberikan jadwal supervisi kepada kepala sekolah terlebih dahulu, dan kepala sekolah menyampaikan kepada guru. Pada waktu yang telah dijadwalkan pengawas sekolah Bpk. Drs. H. Rozali, M.Si datang dan memeriksa berkas administrasi guru yaitu: 1) kalender akademik, 2) program tahunan, 3) program semester, 4) analisis $\mathrm{SK} / \mathrm{KD}, 5$ ) RPP, 6) buku absen, 7) buku nilai, 8) agenda pembelajaran, 9) buku supervisi, 10) kriteria-ketuntasan minimal (KKM). Pengawas sekolah Bpk. Drs.H. Rozali, M.Si menilai dengan sekala liket koponenkomponen yang disupervisi, dan yang menjadi catatan belum ada tindak lanjut dari supervisi kepala sekolah.

Perbedaan supervisi kepala sekolah dengan supervisi pengawas sekolah di SDN 8 Talang Kelapa; 1) berdasar subyek yang di supervisi kepala sekolah mensupervisi guru guna memperbaiki pembelajaran sedang pengawas mensupervisi kepala sekolah dalam bidang manajerial dan supervisi akademik bagi guru. 2) Kepala sekolah jadwalnya lebih fleksibel sedang pengawas sekolah sudah terjadwal. 3) Kepala sekolah mengamati kegiatan belajar mengajar sedang pengawas sekolah hanya mensupervisi administrasi dan persiapan 
mengajar saja. 4) Supervisi Kepala sekolah ditindaklanjuti dengan program kegiatan sekolah, contohnya mengadakan workshop K13 setelah menyimpulkan hasil supervisi guru masih banyak yang belum menguasai K13, sedang pengawas sekolah belum ada tindak lanjut. 5) Guru merasa lebih nyaman di supervisi kepala sekolah dari pada di supervisi pengawas sekolah, dikarenakan guru lebih dekat hubungan personal dengan kepala sekolah.

\section{KESIMPULAN}

Agar para guru mampu melaksanakan tugas-tugas mulia yang menjadi tanggung jawabnya di sekolah perlu senantiasa mendapat penyegaran dalam bentuk bantuan teknis. Bantuan teknis ini diberikan kepada guru sebagai upaya peningkatan kapasitas secara terus menerus. Bantuan tersebut dalam bentuk supervisi akademik yang dilakukan oleh kepala sekolah dan pengawas sekolah.

Supervisi akademik dilakukan untuk mengetahui guru dalam melaksanakan kegiatan pembelajaran mulai dari kegiatan perencanaan, pelaksanaan, dan penilaian. Kepala sekolah dapat mengetahui kompetensi dan kinerja guru dalam kegiatan pembelajaran dari masing-masing guru melalui kegiatan monitoring, pemantauan dan pengawasan pembelajaran di kelas.
Supervisi klinis sebagai upaya yang dirancang secara rasional dan praktis untuk memperbaiki performansi guru di kelas dengan tujuan untuk mengembangkan profesional guru dan perbaikan pengajaran. Ada perbedaan antara supervisi kepala sekolah dengan pengawas sekolah terutama obyek yang disupervisi, jadwal, pelaksanaan, tidak lanjut.

\section{DAFTAR PUSTAKA}

Imron, A. (2011). Supervisi Pembelajaran Tingkat Satuan Pendidikan. Jakarta: Bumi Aksara.

Karsiyem, Muhammad Nur Wangit. (2015). Pelaksanaan Supervisi Akademik Dalam Peningkatan Kinerja Guru Sekolah Dasar Gugus III Sentolo Kulon Progo. Jurnal Akuntabilitas Manajemen Pendidikan. Volume 3, No2, September 2015.

Kristiawan, M. (2015). A Model of Educational Character in High School Al-Istiqamah Simpang Empat, West Pasaman, West Sumatera. Research Journal of Education, 1(2), 15-20.

Kristiawan, M. (2016). Telaah Revolusi Mental Dan Pendidikan Karakter Dalam Pembentukkan Sumber Daya Manusia Indonesia Yang Pandai dan Berakhlak Mulia. Ta'dib, 18(1), 13-25.

Kristiawan, M., \& Elnanda, D. (2017). The Implementation of Authentic Assessment in Cultural History of Islam Subject. $\mathrm{Al}-\mathrm{Ta} \quad \mathrm{lim}$ Journal, 24(3).

Marshall, Kim. (2009). Rethinking Teacher Supervision and Evaluation: How to Work Smart, Build Collaboration, and 
Close the Achivement Gap, San Fransisco: Wiley Imprint.

Maryono. (2011). Dasar-Dasar dan Teknik Menjadi Supervisor Pendidikan. Yogyakarta : Ar-Ruzz Media.

Nazir, Moh, (2009). Metode Penelitian. Bogor: Ghalia Indonesia.

Nugraha, Mulyawan Safwandy. (2015). Pelaksanaan Supervisi Akademik Oleh Kepala Madrasah Aliyah Swasta di Kabupaten Sukabumi Jawa Barat. Jurnal Pendidikan Islam Nadwa. Vol.9,Nomor 1, April 2015.

Peraturan Menteri Pendidikan Nasional Nomor 12 Tahun 2007 Tentang Standar Pengawas Sekolah/Madrasah.

Peraturan Menteri Pendidikan Nasional Nomor 13 Tahun 2007 Tentang Standar Kepala Sekolah/Madrasah.

Peraturan Pemerintah No. 19 tahun 2005 tentang Standarisasi Pendidikan Nasional.

Prasojo, L.D. \& Sudiyono. 2011. Supervisi Pendidikan. Yogyakarta: Gava Media.

Purwanto, M Ngalim. (1991). Administrasi dan supervisi pendidikan. Bandung: Remaja Rosdakarya Offset.

Ramadhan, Ahmad. (2017). Pengaruh Pelaksanaan Supervisi Akademik Pengawas Sekolah Dan Supervisi Kepala Sekolah Terhadap Kinerja Guru SMK Negeri Di Kabupaten Majene. Journal of Educational Science and Technology (EST) Volume 3 Nomor 2 Agustus 2017 Hal. 136144.

Risnawati. (2014). Administrasi dan Supervisi Pendidikan. Yogyakarta: Aswaja Pressindo.
Robbins, P. \& Alvy, H. (2004). The new princhipal's fieldbook stragies for success. Virginia: ASCD.

Sahertian, Piet. (1994). Profil Pendidikan Profesional. Yogyakarta : Andi Offset.

Sagala, H. Syaiful. (2012). Supervisi Pembelajaran dalam Profesi Pendidikan. Bandung: Alfabeta.

Sari, Ajeng Lentika. Sukoco. (2015). Keefektifan Supervisi Akademik oleh Kepala Sekolah Dasar Negeri seKecamatan Talang Empat Bengkulu Tengah. Jurnal Akuntabilitas Manajemen Pendidikan Volume 3, No 1, April 2015 (1-12).

Sudin, Ali (2008). Implementasi Supervisi Akademik Terhadap Proses Pembelajaran di Sekolah Dasar Se Kabupaten Sumedang. "JURNAL, Pendidikan Dasar " Nomor: 9 - April 2008.

Sugiyono. (2007). Memahami Penelitian Kualitatif. Bandung: CV. ALFABETA.

Supardi. (2014). Kinerja Guru. Jakarta: PT. Raja Grafindo Persada.

Undang-Undang Nomor 14 Tahun 2005 Tentang Guru dan Dosen

Undang-Undang Nomor 16 Tahun 2007 tentang standar kualifikasi akademik dan kompetensi guru

Yuliani, T., \& Kristiawan, M. (2017). Peran Kepemimpinan Kepala Sekolah dalam Membina Kompetensi Sosial (Pelayanan Prima) Tenaga Administrasi Sekolah. JMKSP (Jurnal Manajemen, Kepemimpinan, dan Supervisi Pendidikan), 1(2). 